\title{
Localisation du gène du syndrome de Marfan sur le chromosome 15
}

Il y a près d'un siècle, Antoine Marfan, professeur de pédiatrie à Paris, décrivit le syndrome qui porte son nom et qui est devenu le prototype des affections du tissu conjonctif. Sa fréquence est d'environ 50 cas par million, soit près de 3000 en France. Son aspect clinique comporte trois cibles principales, le squelette, l'œil (ectopie du cristallin), le système cardiovasculaire, avec des lésions aortiques souvent responsables d'une mort précoce, et souvent d'autres symptômes associés. L'hérédité autosomique dominante du syndrome a posé, peut-être pour la première fois, la question du pléiotropisme et de la variété clinique dans les maladies monogéniques: un seul locus avec effets multiples, ou plusieurs loci dont la mutation provoquerait des symptômes analogues.

Pour identifier le ou les gènes en cause, on a cru longtemps possible d'avoir recours à la méthode clasșique en désignant une protéine responsable. Alors que de nombreuses anomalies du collagène étaient reconnues, aucune de celles invoquées dans le syndrome de Marfan n'a fait sa preuve. On s'est alors tourné, pour traquer le gène, vers la génétique inverse, à la recherche de liaisons entre la transmission de la maladie et celle de polymorphismes de restriction de marqueurs de chromosomes, grâce à la connaissance de nombreuses familles dans plusieurs pays. Au début de 1990, une étude collective [1] avait permis d'éliminer environ $80 \%$ du génome. Cela facilitait la tâche des chercheurs, et une

chromosome 15 , aboutit à un résultat positif.

L'étude a porté sur 8 familles de Finlande, avec pour chacune au moins 3 sujets atteints vivants. Cinq familles furent inforrmatives, montrant une liaison avec deux marqueurs polymorphes du bras long du chromosome 15. Le lod score atteignait 4. Les 3 autres familles n'étaient pas informatives, sans donner toutefois de lod score négatif. La localisation en 15q21-q22, avec une incertitude de l'ordre de 50 mégabases, soulève un certain nombre d'hypothèses sur les gènes candidats possibles. On connaît notamment dans cette région [2] les gènes codant pour le récepteur du collagène type I, la protéine du chondroïtine sulfate protéoglycane I, et l' $\alpha$-actine cardiaque. Une autre approche part d'anomalies récemment découvertes dans le syndrome de Marfan. Par exemple [3], les microfibrilles du derme sont souvent altérées, et une glycoprotéine appelée fibrilline [4] est mal synthétisée dans les cultures de fibroblastes de ces malades $[5,6]$. Les deux voies pourraient se rejoindre si l'on clone le gène de la fibrilline et si l'on en fait la localisation chromosomique*. Il est également prévu de chercher si des maladies génétiques qui ne comportent qu'une partie des symptômes du Marfan classique pourraient découler d'une altération du même gène. Réciproquement, il est évident que la même analyse doit être menée sur d'autres populations, pour déterminer s'il existe ou non une hétérogénéité génétique.

La seule conséquence pratique actuelle de cette découverte serait la mise au point d'un test de détection préclinique ou prénatal, si on l'estime justifié. Mais elle autorise l'espoir de suivre la route déjà parcourue pour d'autres gènes, aboutissant à l'identification du gène et de la protéine correspondante, point de départ de recherches thérapeutiques futures. Cette route pourrait même être court-circuitée, comme dans le cas des cardiomyopathies hypertrophiques familiales $\left(\mathrm{m} / \mathrm{s} n^{\circ} 9\right.$, vol. 6, p. 920), si les hypothèses sur la protéine responsable, comme la fibrilline, se vérifiaient.

J.-C. D.

1. Blanton SH, Sarfarazi M, Eiberg $\mathrm{H}$, et al. An exclusion map of Marfan syndrome. $J$ Med Genet 1990; $27: 73-7$.

2. Kainulainen K, Pulkkinen L, Savolainen A, Kaitila I, Peltonen L. Location on chromosome 15 of the gene defect causing Marfan syndrome. New Engl J Med $1990 ; 323$ : 935-9. 3. Hollister DW, Sakai LY, Keene DR, Pieritz $\mathrm{RE}$. Immunohistologic abnormalities in the microfibrillar-fiber system in the Marfan syndrome. New Eng J Med 1990 ; 323 : 152-9. 4. Maddox BK, Sakai LY, Keene DR, Glanville RW. Connective tissue microfibrils : isolation and characterization of three large pepsin-resistant domains of fibrillin. $J$ Biol Chem 1989 ; $264: 21381-5$.

5. Pieritz RE. Marfan syndrome. Now Eng $J$ Med 1990; 323 : 987-9.

6. Godfrey M, Menashe V, Welebre RG, et al. Cosegregation of elastin-associated microfibrillar abnormalities with the Marfan phenotype in families. Am J Hum Genet 1990 ; 46 : $652-60$.

* Note ajoutée aux épreuves : $L a$ localisation sur le chromosome 15 du gène de la fibrilline semble se confirmer, selon des informations données au récent congrès américain de génétique humaine qui s'est tenu en octobre 1990 à Cincinnati, dans l'Ohio. 